\title{
Targeting SOX2 as a Therapeutic Strategy in Glioblastoma
}

\author{
Laura Garros-Regulez ${ }^{1 \dagger}$, Idoia Garcia ${ }^{1,2+}$, Estefania Carrasco-Garcia ${ }^{1}$, Aquilino Lantero ${ }^{3}$, \\ Paula Aldaz', Leire Moreno-Cugnon', Olatz Arrizabalaga1, Jose Undabeitia ${ }^{4}$, \\ Sergio Torres-Bayona ${ }^{4}$, Jorge Villanua ${ }^{1,4}$, Irune Ruiz ${ }^{1,4}$, Larraitz Egaña ${ }^{1,4}$, \\ Nicolas Sampron ${ }^{1,4 *}$ and Ander Matheu ${ }^{1,2,4 *}$
}

${ }^{1}$ Cellular Oncology Group, Department of Oncology, Biodonostia Institute, San Sebastian, Spain, ${ }^{2}$ IKERBASQUE Foundation, Billbao, Spain, ${ }^{3}$ Opioid Research Group, Department of Pharmaceutical Chemistry, University of Innsbruck, Innsbruck, Austria, ${ }^{4}$ Neuro-Oncology Committee, Donostia Hospital, San Sebastian, Spain

\section{OPEN ACCESS}

Edited by:

Sabrina Battista,

Consiglio Nazionale delle

Ricerche (CNR), Italy

Reviewed by:

Eumorphia Remboutsika, BSRC "Alexander Fleming", Greece Jihye Paik,

Weill Cornell Medical Collage, USA

*Correspondence: Nicolas Sampron nicolas.sampron@me.com; Ander Matheu ander.matheu@biodonostia.org

${ }^{\dagger}$ Laura Garros-Regulez and Idoia Garcia have contributed equally and should be considered co-first authors.

Specialty section:

This article was submitted to Stem Cell Research, a section of the journal Frontiers in Oncology

Received: 17 August 2016 Accepted: 07 October 2016 Published: 24 October 2016

Citation:

Garros-Regulez L, Garcia I, Carrasco-Garcia E, Lantero A, Aldaz P, Moreno-Cugnon L,

Arrizabalaga O, Undabeitia J, Torres-Bayona S, Villanua J, Ruiz I, Egaña L, Sampron N and Matheu A (2016) Targeting SOX2 as a Therapeutic Strategy in Glioblastoma.

Front. Oncol. 6:222. doi: 10.3389/fonc.2016.00222
Glioblastoma is the most common and malignant brain cancer in adults. Current therapy consisting of surgery followed by radiation and temozolomide has a moderate success rate and the tumor reappears. Among the features that a cancer cell must have to survive the therapeutic treatment and reconstitute the tumor is the ability of self-renewal. Therefore, it is vital to identify the molecular mechanisms that regulate this activity. Sexdetermining region $Y$ (SRY)-box 2 (SOX2) is a transcription factor whose activity has been associated with the maintenance of the undifferentiated state of cancer stem cells in several tissues, including the brain. Several groups have detected increased SOX2 levels in biopsies of glioblastoma patients, with the highest levels associated with poor outcome. Therefore, SOX2 silencing might be a novel therapeutic approach to combat cancer and particularly brain tumors. In this review, we will summarize the current knowledge about SOX2 in glioblastoma and recapitulate several strategies that have recently been described targeting SOX2 in this malignancy.

Keywords: SOX2, glioblastoma, tumor-initiating cells, temozolomide resistance, glioma stem cells, self-renewal inhibition

\section{SOX2}

Sex-determining region Y (SRY)-box (SOX) factors are a family of transcriptional regulators that carry out important functions during embryonic development and which are key components for the maintenance of the stem cells in adult tissues. This family of transcription factors is characterized by a conserved high mobility group (HMG) DNA-binding domain and is composed of 20 members divided into 8 groups (from A to H), based on their HMG sequence identity (1). Members within a subfamily conserve at least $80 \%$ identity in their HMG-domain, in addition to sharing other wellconserved regions. Moreover, members from the same group might have overlapping expression patterns, share biochemical properties, and perform synergistic or redundant functions. By contrast, members from different subgroups usually develop different functions (2).

SOX2 is a member of the SOXB1 group (together with SOX1 and SOX3), which is required for the maintenance of the embryo before implantation. SOX2 has a role in cell fate and maintenance of the progenitors's identity during embryogenesis. It is also important for tissue homeostasis and regeneration by maintaining stem cell activity in several compartments, particularly in the central nervous system (CNS), in adults (3). During recent years, several studies have demonstrated the impact of SOX2 deregulation in a wide variety of human diseases. A heterozygous inactivation of SOX2 causes syndromic microphthalmia-3 (MCOPS3), a genetic disease characterized by anophthalmia, 
microphthalmia mild hypopituitarism, and sometimes learning difficulties, convulsions, motor dysfunctions, and growth problems (4). On the contrary, SOX2 upregulation has been linked to the development and maintenance of several types of cancers $(3,5-7)$.

\section{GLIOBLASTOMA}

Tumors of the CNS form a heterogeneous group of diseases that comprise less than $2 \%$ of the total number of cancer cases. Every year in the world, $\sim 350,000$ people are diagnosed with gliomas, making it the most common primary brain tumor (8). According to clinical and histopathological characteristics, WHO classified them by four grades of malignancy: pylocitic astrocytoma (grade I); diffuse astrocytoma (grade II); anaplastic astrocytoma (grade III), and glioblastoma multiforme (GBM, grade IV). GBM is the most common, malignant, and lethal glioma subtype in adults accounting for $12-15 \%$ of all brain tumors and about $50 \%$ of gliomas. The incidence ranges from 1 to 5 cases per 100,000 people per year, with an average patient survival of around 15 months (8). This prognosis identifies this type of tumor as one of the most aggressive and fatal cancers overall. According to the clinical presentation, there are two main GBM subtypes: primary or de novo GBM and secondary GBM. Primary tumors, the most common form, typically appear in older patients without any prior clinical or histological evidence of a lower grade precursor lesion and they have an aggressive clinical course. Secondary tumors are more frequent in younger people and they progress from a previous lower grade glioma with a less aggressive clinical course (9). Genetic and transcriptomic expression studies have allowed a more detailed molecular classification identifying four GBM subtypes: (i) classical, with EGFR amplification and overexpression, CDKN2A and PTEN deletion, NES overexpression and activation of NOTCH and SHH signaling pathways; (ii) mesenchymal, with loss of NF1, TP53, and PTEN, overexpression of $M E T, C H I 3 L 1, C D 44$, and MERTK, and activation of the TNF and NF-kB pathways; (iii) proneural, with PDGFR amplification, loss or mutation of IDH1, PIK3K, TP53, CDKN2A, and PTEN, and activation of HIF, PI3K, and PDGFR pathways; and (iv) neural, with EGFR amplification and overexpression, and expression of neuronal markers, such as NEFL, SYT1, and/or GABRA1 (10). Different subtypes are associated with variable prognosis and response to therapy, and this heterogeneity and this therapy resistance are likely the main characteristics responsible for the glioblastoma patients' dismal outcome.

The cancer stem cell (CSC) theory postulates a hierarchically organized system in opposition to the stochastic model of tumor growth. The CSC model suggests that only a small group of cells have quiescence and self-renewal capacity within the tumor bulk, and that those are responsible for tumor maintenance and recurrence (11). Nowadays, there is a lot of evidence that supports the existence of CSCs in GBM, called glioma stem cells (GSC), and their relevance in the etiology of GBM. Several groups have been able to isolate GSCs from patient-derived tumors and multiple experimental data have shown that these cells are responsible for glioblastoma initiation and maintenance $(12,13)$, as well as for recurrence and chemoresistance (14-16). Moreover, there are different explanations for their origin. One of them proposes that neural stem cells (NSCs) undergo malignant transformation while retaining stem cell features. Indeed, inactivation of TP53, INK4a/ $A R F$ locus, PTEN, and NF1 tumor suppressors or activation of EGFR/PDGFR/PI3K oncogenic pathways in NSCs induces highgrade gliomas (17). Similarly, transient amplifying progenitors have been also shown as GSCs and the cell of origin of GBM (18). Another theory claims that more mature or differentiated cells are reprogrammed and form GSCs and high-grade gliomas. Indeed, several mutations in astrocytes, oligodendrocyte progenitors, or in neurons are sufficient to confer stem cell properties during neoplastic transformation $(19,20)$. Therefore, in order to establish efficient treatments that can induce a long-lasting clinical response in GBM, it is important to develop strategies that can specifically target GSCs (Figure 1A). CSCs, including GSCs, achieve selfrenewal through asymmetric division, in which one daughter cell retains the self-renewal ability, and the other is directed to differentiation. Moreover, heterogeneous tumor cell populations and their respective cell division mode have been shown to confer differential sensitivity to therapy in brain tumors (21). Therefore, modulation of asymmetric and symmetric division of GSCs may provide novel strategies for targeting differentially the GSC and the bulk tumor mass. Several drugs and approaches have been postulated (22) to directly target the GSCs population and/or the molecular mechanisms underlying their regulation. In this review, we focused our attention on targeting SOX2 gene.

\section{SOX2 ACTIVITY AND GBM}

Several studies have identified an overexpression of SOX2 in GBM patient samples. It was first found elevated in $90 \%$ of human biopsies studied at the mRNA and protein level in 2007. This research also showed that SOX2 expression was restricted to the nucleus (23). Since then, overexpression of SOX2 (with varying percentages of positive cases) was observed in several different and independent cohorts (16, 24-27). Importantly, high levels of SOX2 have been associated with tumor aggressiveness and worse prognosis $(28,29)$. Moreover, several groups, including ours, identified SOX2 enrichment in the undifferentiated GSC populations and demonstrated that SOX2 possesses an important role in the maintenance of GSCs. Indeed, downregulation of SOX2 through RNA interference strategies in GSCs impairs proliferation and their ability to form tumors in vivo (25, 30-32). Additionally, silencing of SOX2 leads to reduced migration and invasion capabilities $(25,33)$, while it increases senescence and produces an arrest of the cell cycle in G0/G1 $(16,34)$. The impact of SOX2 in glioblastoma cells has been further substantiated with overexpression studies. Indeed, ectopic elevation of SOX2 increases the capacity of invasion and migration (25), in addition to cell proliferation and self-renewal activity in conventional glioma cell lines (16). In agreement with this last function, SOX2 is one of the transcription factors, together with POU3F2, OLIG2, and SALL2, which is sufficient to reprogram differentiated glioma cells into induced GSCs, similar to GSCs obtained from human biopsies (35). Altogether these data show that glioma cells have a dependence on SOX2 to maintain their tumorigenic activity with GSCs displaying high levels of SOX2. 


\section{A}

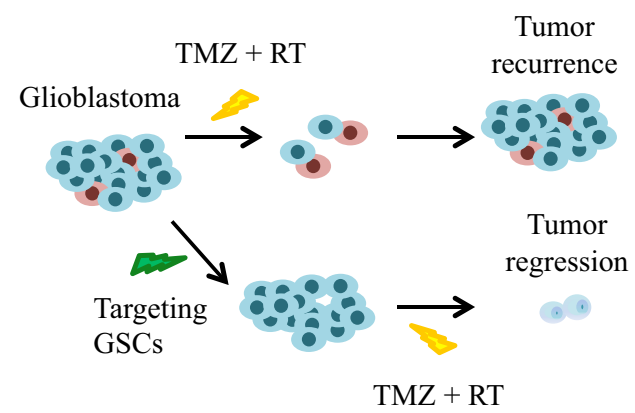

B

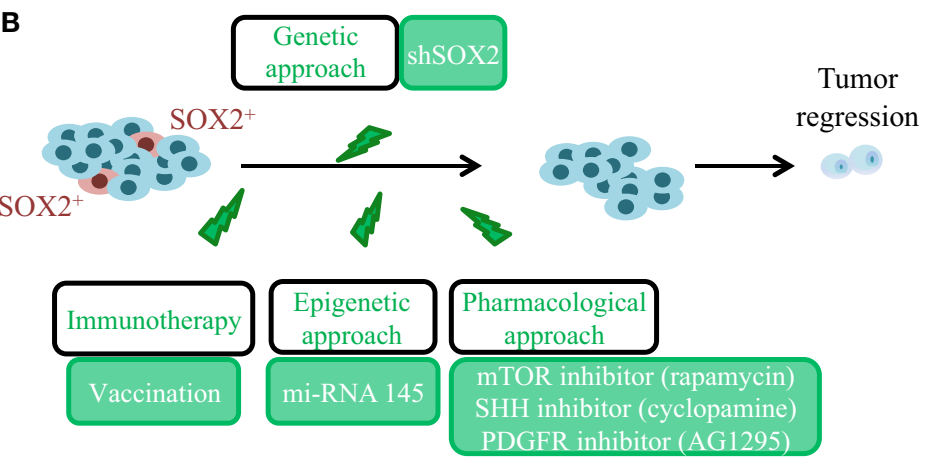

Tumor cell

GSC

FIGURE 1 | Significance of glioma stem cells (GSCs) and SOX2 targeting in the recurrence of glioblastoma. (A) Glioblastoma is a heterogeneous tumor composed of GSCs (in red, chemo-, and radiotherapy resistant) and of differentiated tumor cells (in blue, chemo-, and radiotherapy responsive). GSCs need to be targeted before current standard approaches to achieve tumor regression. TMZ, temozolomide; RT, radiotherapy. (B) In order to avoid tumor recurrence, genetic, epigenetic, and pharmacological approaches targeting GSCs expressing high levels of SOX2 have been postulated.

They also demonstrate that SOX2 possesses an important role in the maintenance of GSCs.

In regard to a putative role of SOX 2 controlling cell division modes, a recent work showed that the inhibition of the FACT chaperone complex in GSCs promotes their asymmetrical division in a process that involves SOX2 downregulation (36). In line with these results, other authors found that the knockdown of HMGA1, a chromatin structure regulator, not only in GSCs but also in colon CSCs, induces an asymmetric division together with a decrease in SOX2 expression $(37,38)$. These works suggest that SOX2 action in the maintenance of undifferentiated GSCs could rely on effects promoting symmetrical in addition to the expected asymmetrical division. Importantly, these results support a hierarchical model of glioma cells controlled by SOX2 expression, which brings up the idea to target SOX2 or to find downstream targetable genes as a strategy to eliminate GSCs and subsequently the tumor.

\section{UPSTREAM REGULATION OF SOX2}

The regulation of SOX2 is a complex network of transcriptional, post-transcriptional, and post-translational regulators (Table 1). Some of these regulators are altered in GBM and lead to the overexpression of SOX2. Four main signaling pathways are involved in SOX2 expression, including TGF- $\beta$, SHH, EGFR, and FGFR. All these signaling pathways are aberrantly activated in GBM, which leads to the maintenance of the tumor at least in part through SOX2 factor overexpression. The inhibition of TGF- $\beta$ signaling decreases the tumorigenicity of GSCs by the suppression of SOX2 activity (31). SOX2 function is also mediated by other members of the SOX family, such as SOX 4 , acting downstream of the TGF- $\beta$ signaling pathway, and forming a complex with OCT4 at the SOX2 promoter $(31,39)$. SHH pathway is initiated with the binding of $\mathrm{SHH}$ ligand to PTCH receptor, causing the activation of SMO. Active SMO will activate GLI1/2, which then translocates into the nucleus and activates SOX2. The regulation of SOX2 by SHH
TABLE 1 | Summary of relevant findings of SOX2 in glioblastoma.

\begin{tabular}{|c|c|c|}
\hline Year & Finding & Reference \\
\hline 2007 & $\begin{array}{l}\text { SOX2 is overexpressed in human glioma } \\
\text { samples }\end{array}$ & Schmitz et al. (23) \\
\hline 2009 & Genetic SOX2 silencing impairs GSCs activity & Gangemi et al. (30) \\
\hline 2011 & $\begin{array}{l}\text { Identification of SOX2 downstream targets in } \\
\text { GBM with miRNA145-SOX2 feedback loop }\end{array}$ & Fang et al. (48) \\
\hline 2011 & $\begin{array}{l}\text { Genetic and epigenetic regulation of SOX2 in } \\
\text { GBM samples }\end{array}$ & Alonso et al. (25) \\
\hline 2011 & $\begin{array}{l}\text { Identification of SOX2 as a target for } \\
\text { combination treatments with tyrosine-kinase } \\
\text { inhibitors }\end{array}$ & $\begin{array}{l}\text { Hägerstrand et al. } \\
(32)\end{array}$ \\
\hline 2011 & $\begin{array}{l}\text { Identification of SOX2 downstream of TGF- } \beta \\
\text { signaling in GSCs }\end{array}$ & Ikushima et al. (31) \\
\hline 2014 & $\begin{array}{l}\text { Elevated SOX2 promotes dedifferentiation and } \\
\text { acquisition of GSC characteristics in GBM cells }\end{array}$ & Suvà et al. (35) \\
\hline 2007 & First results supporting SOX2 mediated & Schmitz et al. (23) \\
\hline $\begin{array}{l}\text { and } \\
2014\end{array}$ & $\begin{array}{l}\text { immunotherapy in mouse models and human } \\
\text { samples }\end{array}$ & Favaro et al. (41) \\
\hline 2016 & $\begin{array}{l}\text { SOX2 induces chemoresistance, which is } \\
\text { inhibited by rapamycin }\end{array}$ & $\begin{array}{l}\text { Garros-Regulez } \\
\text { et al. (16) }\end{array}$ \\
\hline
\end{tabular}

occurs in neural and brain stem cells $(40,41)$, and the pharmacological inhibition of these pathways silences SOX2 expression and impairs glioma cells' tumorigenic activity (16). The FGFR pathway regulates SOX2 expression through two main signaling cascades: (i) MEK/ERK and (ii) PI3K/AKT/mTOR, two signaling pathways activated in GBM, and whose suppression leads to the inhibition of tumorigenesis and self-renewal of GSCs (42). The MEK/ERK pathway regulates the expression of SOX2 through the final phosphorylation of ERK, which translocates into the nucleus and activates the transcription of SOX2. The PI3K/AKT/mTOR pathway regulates positively the expression of SOX2 through the activation of the mammalian target of rapamycin complex 1 (mTORC1). The inhibition of mTORC1 by rapamycin in GSCs leads to an inhibition of the SOX2 expression and a decrease in self-renewal activity (16). SOX2 is also regulated by EGFRvIII, 
a frequent mutant in GBM that leads to the activation of prooncogenic signaling in GBM. Indeed, the expression of EGFRvIII positively correlates with the expression of SOX2 and is associated with an enhanced self-renewal ability and tumor-initiating activity (43). This correlation has demonstrated that it is carried out by the axis EGFRvIII-STAT3-PEDF-Notch (44).

SOX2 can also be regulated via post-translational modifications, such as ubiquitination, phosphorylation, and acetylation. Acetylation and phosphorylation enhance the export of SOX2 to the cytoplasm and inhibit the ability to bind DNA in embryonic stem cells $(45,46)$. By contrast, the phosphorylation of SOX2 by AKT stabilizes the protein and enhances the transcriptional activity of SOX2 (47). However, the function of these modifications in GSCs' activity remains elusive.

Additionally, SOX2 genetic amplification and promoter DNA hypomethylation has been identified in a set of GBM patients, further expanding the mechanism responsible for SOX2 upregulation in glioblastoma samples and GSCs (25). Moreover, the regulation of SOX2 through different miRNAs, including miRNA21 or miRNA145, has been described in glioma cells, with this axis having relevant functions in GSCs' activity and in the clinic $(29,48)$.

\section{DOWNSTREAM REGULATION OF SOX2}

Several studies have started to characterize downstream targets of SOX2 in glioblastoma. A study of Fang et al. identified SOX2 downstream targets by ChIP-seq and microarray analyses in the LN229 glioma cell line. They found 4,883 SOX2 binding regions in the GBM cancer genome. Moreover, they detected 489 genes whose expression was altered with SOX2 inhibition, including additional SOX family members, cytokines, or BEX members with tumor suppressor activity in glioblastoma. They also identified 105 pre-miRNAs (corresponding to 95 mature miRNAs) that were differentially expressed in SOX2 knockdown glioblastoma cells. Among them, they observed that miRNA145 and SOX2 form a double-negative feedback loop in GBM cells (48), demonstrating that the relationship between SOX2 and miRNA is bidirectional. We have recently observed that several oncogenic SOX2 functions are mediated by SOX9, another member of the SOX family (16), which also carries out important functions in GSC regulation and glioblastoma (26). This regulation occurs at post-transcriptional level (16). Additionally, specific phenotypes associated with SOX2 have been linked to different genes and signaling pathways. Indeed, SOX2-regulated migratory and invasive capacities are mediated by RhoA-dependent pathway and focal adhesion kinase (FAK) signaling, whereas proliferation is mediated by CYCLIN D1 expression (34). WNT signaling pathway, self-renewal, and retinoic acid associated genes are within the genes involved in SOX2-mediated glioma cell plasticity and astrocytic differentiation (49).

\section{THERAPEUTIC APPROACHES TOWARD SOX2 REDUCTION IN GBM}

The current chemotherapeutic agent for newly diagnosed GBM is temozolomide (TMZ), which extends patient survival from
12 to 15 months (50). A role for SOX2 in TMZ chemoresistance has been deciphered during recent years. Thus, cells with elevated SOX2 expression are more resilient to TMZ, whereas its inhibition sensitizes glioma cells to this agent (16). This cellular finding is correlated with clinical information. High levels of SOX2 have been included as a marker of the proneural subtype, which has been shown to be the most resistant subgroup to current therapeutic radio- and chemotherapy treatment (10). The involvement of SOX2 in chemoresistance has been further substantiated through different mechanisms. The inhibition of SOX2 by miRNA145 decreases the chemoresistance of GSCs and increases the sensitivity to radiation and TMZ (51). The overexpression of ID-4 suppresses the expression of miRNA9, that can repress SOX2, leading to an increase in the SOX2 expression. SOX2 induction enhances the ATP-binding cassette (ABC) transporters, ABCC3 and $\mathrm{ABCC} 6$, through direct transcriptional regulation. The activation of $\mathrm{ABC}$ transporters confers chemoresistance to GSCs (52). These facts together with its prominent role in the regulation of GSCs suggest that SOX2 might be a key responsible factor for resistance to current chemotherapy and postulate that targeting its activity may offer a novel, attractive therapeutic approach to treat glioblastoma patients.

Several strategies are starting to use SOX2 directly or indirectly to target GSCs (Figure 1B). PDGFR signaling has been involved in glioblastoma biology through studies based on analyses of human tumor tissue, cultured glioblastoma cells, and mouse glioblastoma models (22). Similarly, IGF1-R signaling has been described in glioblastoma, and findings from preclinical studies suggest favorable combination effects when IGF1-R inhibitors have been combined with other receptor tyrosine-kinase (RTK)targeting agents. Interestingly, a combination therapy with PDGF and IGF1 receptor inhibitors (imatinib and NVP-AEW541) produces a significant tumor growth reduction through SOX2 downregulation and GSC sensitization (32).

Rapamycin is an allosteric inhibitor of mTOR, which has been shown to dramatically reduce the self-renewal and tumorigenic activity of glioma cells and GSCs (53). In agreement with these results, several phase I and II clinical trials, with some of its rapalogs, such as everolimus or temsirolimus, alone or in combination, showed radiographic and symptomatic evidence of improvement in delaying tumor progression without provoking high toxicity in patients with newly diagnosed or recurrent glioblastoma (54). It has recently been demonstrated that mTOR regulates the expression of SOX2. Genetic mTOR silencing or pharmacological treatment with rapamycin markedly reduced SOX2 levels in glioma cells (16). Interestingly, the same work showed that the combination of rapamycin and TMZ was more efficient and displayed increased cytotoxicity in cells with high endogenous SOX2 levels (16). Cyclopamine, an inhibitor of the $\mathrm{SHH}$ pathway, was also proved effective in reducing SOX2 expression and inducing cytotoxicity in in vitro studies, but unlike rapamycin, its combination with TMZ did not increase the sensitivity of glioma cells to chemotherapy (16). Furthermore, several studies have demonstrated the capability of the GSCs to transdifferentiate into tumor-derived vascular endothelial and mural-like cells in a VEGF-independent manner, making the tumor resistant to anti-vascular therapy $(55,56)$. This 
transdifferentiation relies on high levels of NESTIN and CD133 stem markers; however, SOX2 has not been evaluated. It would be of interest to determine the role of SOX2 in transdifferentiation and if knocking down its expression levels is sufficient to prevent the process.

Alternative treatments are arising using SOX2 protein as the principal target of new therapies. Immunotherapy represents a promising treatment option to improve the clinical outcome of patients suffering from GBM. In 2014, Dr Nicolis' group did transplants of GSCs in mice brains using peptide vaccination against SOX2. Peptide vaccination alone increased the mice' survival and the vaccination in combination with the current treatment with TMZ doubled the mice' survival time (41). Before, Schmitz and coworkers identified SOX2 as a glioma-associated antigen abundantly and specifically overexpressed in glioma cells. In addition, they identified an immunogenic HLA-A ${ }^{\star} 0201-$ restricted T-cell epitope derived from SOX2 that effectively activated tumor-directed cytotoxic T lymphocytes (23). These results highlight the suitability of SOX2 for a novel strategy based in immunotherapy in monotherapy or in combination with current therapies for the treatment of glioblastoma patients.

The use of miRNA delivery could be another therapy linked to SOX2 for cancer cells in the brain. As described above, miRNA145 is associated with SOX2. Interestingly, miRNA145 delivery in GSCs and in xenograft studies in vivo demonstrated the ability to suppress the tumorigenicity by direct downregulation of SOX2 protein with cells becoming more sensitive to chemotherapeutic agents, such as TMZ or cisplatin (51). The promising therapeutic prospect of miR-145 might improve current cancer treatments, especially for those tumors that have developed a resistance to conventional therapeutic methods. However, a note of caution needs to be included since the use of viral vectors for gene delivery may be accompanied by several problems, including an immune response.

\section{CONCLUDING REMARKS}

Glioblastoma is the most common and malignant adult primary brain tumor with a dismal patient prognosis. It is characterized by presenting significant heterogeneity at the genetic, molecular, cellular, and morphological level, which severely affects clinical practice. Tumor bulk is formed by differentiated cells targetable with chemo- and radiotherapy and GSCs, which need to be eradicated in order to achieve effective therapeutic response.

\section{REFERENCES}

1. Kamachi Y, Kondoh H. Sox proteins: regulators of cell fate specification and differentiation. Development (2013) 140:4129-44. doi:10.1242/dev.091793

2. Wegner M. All purpose Sox: the many roles of Sox proteins in gene expression. Int J Biochem Cell Biol (2009) 42:381-90. doi:10.1016/j.biocel.2009. 07.006

3. Sarkar A, Hochedlinger $\mathrm{K}$. The sox family of transcription factors: versatile regulators of stem and progenitor cell fate. Cell Stem Cell (2013) 12:15-30. doi:10.1016/j.stem.2012.12.007

4. Kelberman D, Rizzoti K, Avilion A, Bitner-Glindzicz M, Cianfarani S, Collins J, et al. Mutations within Sox2/SOX2 are associated with abnormalities in the hypothalamo-pituitary-gonadal axis in mice and humans. J Clin Invest (2006) 116:2442-55. doi:10.1172/JCI28658
Sex-determining region Y (SRY)-box 2 transcription factor is important during embryonic development and for the maintenance of stem cell properties of the CNS in adult and aged stages $(3,57,58)$. It is also a key regulator of stemness in CSCs and its biological function has been widely described in GBM, associated with stemness activity and a poor clinical outcome (Table 1). Therefore, SOX2 is a strong molecular candidate to be targeted in glioblastoma samples and the potential benefit of SOX2 targeting in the scenario of such a lethal tumor is not negligible. However, a point to take into account with regard to SOX2 targeting for GBM treatment is that other SOX2 expressing cell populations as astrocytes, which develop relevant roles in neurogenesis, could be susceptible to the treatments. The consequences of this must be evaluated and other molecules acting downstream of SOX2, and more specific of GSCs, should be identified and considered as targets.

Transcriptional regulation and/or post-transcriptional suppression of SOX2 through miRNA regulation are promising approaches. There are also encouraging results with SOX2 immunotherapy or combining tyrosine-kinase and IGF1 inhibitors. These results show the preclinical proof of concept that silencing SOX2 activity is an effective strategy in glioblastoma. More solid and extensive preclinical results and clinical trials with the postulated combination of therapies in glioblastoma patients whose biopsies express elevated SOX2 are needed to establish their clinical impact.

\section{AUTHOR CONTRIBUTIONS}

LG-R and IG, first authors of the review, wrote most of the review. NS and AM, senior authors, designed the review, directed the work, and wrote the manuscript. The additional authors suggested ideas and revised the manuscript.

\section{FUNDING}

LG-R, LM-C, and OA are recipients of a predoctoral fellowship from the Department of Education, Universities and Research of the Basque Government. PA is in receipt of a predoctoral fellowship from the Spanish Association Against Cancer (AECC Gipuzkoa). This work was supported by grants from the Spanish Ministry of Economy and Competition (CP10/00539, PI13/02277) and the European Union (Marie Curie CIG 2012/712404, REFBIO13/ BIOD/009 and 011) for AM.

5. Bass AJ, Watanabe H, Mermel CH, Yu S, Perner S, Verhaak RG, et al. SOX2 is an amplified lineage-survival oncogene in lung and esophageal squamous cell carcinomas. Nat Genet (2009) 41:1238-42. doi:10.1038/ng.465

6. Li H, Collado M, Villasante A, Matheu A, Lynch CJ, Cañamero M, et al. p27(Kip1) directly represses Sox2 during embryonic stem cell differentiation. Cell Stem Cell (2012) 11:845-52. doi:10.1016/j.stem.2012.09.014

7. Carrasco-Garcia E, Santos JC, Garcia I, Brianti M, García-Puga M, Pedrazzoli J Jr, et al. Paradoxical role of SOX2 in gastric cancer. Am J Cancer Res (2016) 6:701-13.

8. Ostrom QT, Bauchet L, Davis FG, Deltour I, Fisher JL, Langer CE, et al. The epidemiology of glioma in adults: a "state of the science" review. Neuro Oncol (2014) 16:896-913. doi:10.1093/neuonc/nou087

9. Ohgaki $\mathrm{H}$, Kleihues $\mathrm{P}$. The definition of primary and secondary glioblastoma. Clin Cancer Res (2013) 19:764-72. doi:10.1158/1078-0432.CCR-12-3002 
10. Verhaak RG, Hoadley KA, Purdom E, Wang V, Qi Y, Wilkerson MD, et al. Integrated genomic analysis identifies clinically relevant subtypes of glioblastoma characterized by abnormalities in PDGFRA, IDH1, EGFR, and NF1. Cancer Cell (2010) 17:98-110. doi:10.1016/j.ccr.2009.12.020

11. Pattabiraman DR, Weinberg RA. Tackling the cancer stem cells - what challenges do they pose? Nat Rev Drug Discov (2014) 13:497-512. doi:10.1038/ $\operatorname{nrd} 4253$

12. Galli R, Binda E, Orfanelli U, Cipelletti B, Gritti A, De Vitis S, et al. Isolation and characterization of tumorigenic, stem-like neural precursors from human glioblastoma. Cancer Res (2004) 64:7011-21. doi:10.1158/0008-5472. CAN-04-1364

13. Singh SK, Hawkins C, Clarke ID, Squire JA, Bayani J, Hide T, et al. Identification of human brain tumour initiating cells. Nature (2004) 432:396-401. doi: $10.1038 /$ nature 03128

14. Bao S, Wu Q, McLendon RE, Hao Y, Shi Q, Hjelmeland AB, et al. Glioma stem cells promote radioresistance by preferential activation of the DNA damage response. Nature (2006) 444:756-60. doi:10.1038/nature05236

15. Chen J, Li Y, Yu TS, McKay RM, Burns DK, Kernie SG, et al. A restricted cell population propagates glioblastoma growth after chemotherapy. Nature (2012) 488:522-6. doi:10.1038/nature11287

16. Garros-Regulez L, Aldaz P, Arrizabalaga O, Moncho-Amor V, Carrasco-Garcia E, Manterola L, et al. mTOR inhibition decreases SOX2-SOX9 mediated glioma stem cell activity and temozolomide resistance. Expert Opin Ther Targets (2016) 20:393-405. doi:10.1517/14728222.2016.1151002

17. Alcantara Llaguno S, Chen J, Kwon CH, Jackson EL, Li Y, Burns DK, et al. Malignant astrocytomas originate from neural stem/progenitor cells in a somatic tumor suppressor mouse model. Cancer Cell (2009) 15:45-56. doi:10.1016/j.ccr.2008.12.006

18. Alcantara Llaguno SR, Wang Z, Sun D, Chen J, Xu J, Kim E, et al. Adult lineage-restricted CNS progenitors specify distinct glioblastoma subtypes. Cancer Cell (2015) 28:429-40. doi:10.1016/j.ccell.2015.09.007

19. Persson AI, Petritsch C, Swartling FJ, Itsara M, Sim FJ, Auvergne R, et al. Non-stem cell origin for oligodendroglioma. Cancer Cell (2010) 18:669-82. doi:10.1016/j.ccr.2010.10.033

20. Friedmann-Morvinski D, Bushong EA, Ke E, Soda Y, Marumoto T, Singer O, et al. Dedifferentiation of neurons and astrocytes by oncogenes can induce gliomas in mice. Science (2012) 338:1080-4. doi:10.1126/science. 1226929

21. Lewis KM, Petritsch C. Asymmetric cell division: implications for glioma development and treatment. Transl Neurosci (2013) 4:484-503. doi:10.2478/ s13380-013-0148-8

22. Carrasco-Garcia E, Sampron N, Aldaz P, Arrizabalaga O, Villanua J, Barrena C, et al. Therapeutic strategies targeting glioblastoma stem cells. Recent Pat Anticancer Drug Discov (2013) 8:216-27. doi:10.2174/157489281 13089990002

23. Schmitz M, Temme A, Senner V, Ebner R, Schwind S, Stevanovic S, et al. Identification of SOX2 as a novel glioma-associated antigen and potential target for T cell-based immunotherapy. Br JCancer (2007) 96:1293-301. doi:10.1038/sj.bjc.6603802

24. Annovazzi L, Mellai M, Caldera V, Valente G, Schiffer D. SOX2 expression and amplification in gliomas and glioma cell lines. Cancer Genomics Proteomics (2011) 8:139-47.

25. Alonso MM, Diez-Valle R, Manterola L, Rubio A, Liu D, Cortes-Santiago N, et al. Genetic and epigenetic modifications of Sox 2 contribute to the invasive phenotype of malignant gliomas. PLoS One (2011) 6:e26740. doi:10.1371/ journal.pone.0026740

26. de la Rocha AM, Sampron N, Alonso MM, Matheu A. Role of SOX family of transcription factors in central nervous system tumors. Am J Cancer Res (2014) 4:312-24.

27. Brennan CW, Verhaak RG, McKenna A, Campos B, Noushmehr H, Salama SR, et al. The somatic genomic landscape of glioblastoma. Cell (2013) 155:462-77. doi:10.1016/j.cell.2013.09.034

28. Ben-Porath I, Thomson MW, Carey VJ, Ge R, Bell GW, Regev A, et al. An embryonic stem cell-like gene expression signature in poorly differentiated aggressive human tumors. Nat Genet (2008) 40:499-507. doi:10.1038/ ng. 127

29. Sathyan P, Zinn PO, Marisetty AL, Liu B, Kamal MM, Singh SK, et al. Mir-21Sox2 axis delineates glioblastoma subtypes with prognostic impact. J Neurosci (2015) 35:15097-112. doi:10.1523/JNEUROSCI.1265-15.2015
30. Gangemi RM, Griffero F, Marubbi D, Perera M, Capra MC, Malatesta P, et al. SOX2 silencing in glioblastoma tumor-initiating cells causes stop of proliferation and loss of tumorigenicity. Stem Cells (2009) 27:40-8. doi:10.1634/ stemcells.2008-0493

31. Ikushima H, Todo T, Ino Y, Takahashi M, Miyazawa K, Miyazono K. Autocrine TGF-beta signaling maintains tumorigenicity of glioma-initiating cells through Sry-related HMG-box factors. Cell Stem Cell (2009) 5:504-14. doi:10.1016/j.stem.2009.08.018

32. Hägerstrand D, He X, Bradic Lindh M, Hoefs S, Hesselager G, Ostman A, et al. Identification of a SOX2-dependent subset of tumor- and sphere-forming glioblastoma cells with a distinct tyrosine kinase inhibitor sensitivity profile. Neuro Oncol (2011) 13:1178-91. doi:10.1093/neuonc/nor113

33. Velpula KK, Dasari VR, Tsung AJ, Dinh DH, Rao JS. Cord blood stem cells revert glioma stem cell EMT by down regulating transcriptional activation of Sox2 and Twist1. Oncotarget (2011) 2:1028-42. doi:10.18632/oncotarget.367

34. Oppel F, Müller N, Schackert G, Hendruschk S, Martin D, Geiger KD, et al. SOX2-RNAi attenuates S-phase entry and induces RhoA-dependent switch to protease-independent amoeboid migration in human glioma cells. Mol Cancer (2011) 10:137. doi:10.1186/1476-4598-10-137

35. Suvà ML, Rheinbay E, Gillespie SM, Patel AP, Wakimoto H, Rabkin SD, et al. Reconstructing and reprogramming the tumor-propagating potential of glioblastoma stem-like cells. Cell (2014) 157:580-94. doi:10.1016/j. cell.2014.02.030

36. Dermawan JK, Hitomi M, Silver DJ, Wu Q, Sandlesh P, Sloan AE, et al. Pharmacological targeting of the histone chaperone complex FACT preferentially eliminates glioblastoma stem cells and prolongs survival in preclinicalmodels.CancerRes(2016)76:2432-42.doi:10.1158/0008-5472.CAN15-2162

37. Colamaio M, Tosti N, Puca F, Mari A, Gattordo R, Kuzay Y, et al. HMGA1 silencing reduces stemness and temozolomide resistance in glioblastoma stem cells. Expert Opin Ther Targets (2016) 20:1169-79. doi:10.1080/14728222. 2016.1220543

38. Puca F, Colamaio M, Federico A, Gemei M, Tosti N, Bastos AU, et al. HMGA1 silencing restores normal stem cell characteristics in colon cancer stem cells by increasing p53 levels. Oncotarget (2014) 5:3234-45. doi:10.18632/ oncotarget.1914

39. Ikushima H, Todo T, Ino Y, Takahashi M, Saito N, Miyazawa K, et al. Gliomainitiating cells retain their tumorigenicity through integration of the Sox axis and Oct4 protein. J Biol Chem (2011) 286:41434-41. doi:10.1074/jbc. M111.300863

40. Favaro R, Valotta M, Ferri AL, Latorre E, Mariani J, Giachino C, et al. Hippocampal development and neural stem cell maintenance require Sox2dependent regulation of Shh. Nat Neurosci (2009) 12:1248-56. doi:10.1038/ nn.2397

41. Favaro R, Appolloni I, Pellegatta S, Sanga AB, Pagella P, Gambini E, et al. Sox2 is required to maintain cancer stem cells in a mouse model of high-grade oligodendroglioma. Cancer Res (2014) 74:1833-44. doi:10.1158/0008-5472. CAN-13-1942

42. Sunayama J, Matsuda K, Sato A, Tachibana K, Suzuki K, Narita Y, et al. Crosstalk between the PI3K/mTOR and MEK/ERK pathways involved in the maintenance of self-renewal and tumorigenicity of glioblastoma stem-like cells. Stem Cells (2010) 28:1930-9. doi:10.1002/stem.521

43. Emlet DR, Gupta P, Holgado-Madruga M, Del Vecchio CA, Mitra SS, Han SY, et al. Targeting a glioblastoma cancer stem-cell population defined by EGF receptor variant III. Cancer Res (2014) 74:1238-49. doi:10.1158/0008-5472. CAN-13-1407

44. Yin J, Park G, Kim TH, Hong JH, Kim YJ, Jin X, et al. Correction: pigment epithelium-derived factor (PEDF) expression induced by EGFRvIII promotes self-renewal and tumor progression of glioma stem cells. PLoS Biol (2016) 14:e1002367. doi:10.1371/journal.pbio.1002367

45. Baltus GA, Kowalski MP, Zhai H, Tutter AV, Quinn D, Wall D, et al. Acetylation of sox2 induces its nuclear export in embryonic stem cells. Stem Cells (2009) 27:2175-84. doi:10.1002/stem.168

46. Van Hoof D, Muñoz J, Braam SR, Pinkse MW, Linding R, Heck AJ, et al. Phosphorylation dynamics during early differentiation of human embryonic stem cells. Cell Stem Cell (2009) 5:214-26. doi:10.1016/j.stem.2009. 05.021

47. Fang L, Zhang L, Wei W, Jin X, Wang P, Tong Y, et al. A methylation-phosphorylation switch determines Sox2 stability and function in ESC maintenance 
or differentiation. Mol Cell (2014) 55:537-51. doi:10.1016/j.molcel.2014. 06.018

48. Fang X, Yoon JG, Li L, Yu W, Shao J, Hua D, et al. The SOX2 response program in glioblastoma multiforme: an integrated ChIP-seq, expression microarray, and microRNA analysis. BMC Genomics (2011) 12:11. doi:10.1186/1471-2164-12-11

49. Berezovsky AD, Poisson LM, Cherba D, Webb CP, Transou AD, Lemke NW, et al. Sox2 promotes malignancy in glioblastoma by regulating plasticity and astrocytic differentiation. Neoplasia (2014) 16:e119-25. doi:10.1016/j. neo.2014.03.006

50. Stupp R, Mason WP, van den Bent MJ, Weller M, Fisher B, Taphoorn MJ, et al. Radiotherapy plus concomitant and adjuvant temozolomide for glioblastoma. N Engl J Med (2005) 352:987-96. doi:10.1056/NEJMoa043330

51. Yang YP, Chien Y, Chiou GY, Cherng JY, Wang ML, Lo WL, et al. Inhibition of cancer stem cell-like properties and reduced chemoradioresistance of glioblastoma using microRNA145 with cationic polyurethane-short branch PEI. Biomaterials (2012) 33:1462-76. doi:10.1016/j.biomaterials.2011. 10.071

52. Jeon HM, Sohn YW, Oh SY, Kim SH, Beck S, Kim S, et al. ID4 imparts chemoresistance and cancer stemness to glioma cells by derepressing miR- $9^{*}$-mediated suppression of SOX2. Cancer Res (2011) 71:3410-21. doi:10.1158/0008-5472. CAN-10-3340

53. Arcella A, Biagioni F, Antonietta Oliva M, Bucci D, Frati A, Esposito V, et al. Rapamycin inhibits the growth of glioblastoma. Brain Res (2013) 1495:37-51. doi:10.1016/j.brainres.2012.11.044

54. Pachow D, Wick W, Gutmann DH, Mawrin C. The mTOR signaling pathway as a treatment target for intracranial neoplasms. Neuro Oncol (2015) 17:189-99. doi:10.1093/neuonc/nou164
55. Soda Y, Marumoto T, Friedmann-Morvinski D, Soda M, Liu F, Michiue H, et al. Transdifferentiation of glioblastoma cells into vascular endothelial cells. Proc Natl Acad Sci U S A (2011) 108:4274-80. doi:10.1073/pnas.1016030108

56. Scully S, Francescone R, Faibish M, Bentley B, Taylor SL, Oh D, et al. Transdifferentiation of glioblastoma stem-like cells into mural cells drives vasculogenic mimicry in glioblastomas. J Neurosci (2012) 32:12950-60. doi:10.1523/JNEUROSCI.2017-12.2012

57. Brazel CY, Limke TL, Osborne JK, Miura T, Cai J, Pevny L, et al. Sox2 expression defines a heterogeneous population of neurosphere-forming cells in the adult murine brain. Aging Cell (2005) 4:197-207. doi:10.1111/j.14749726.2005.00158.x

58. Carrasco-Garcia E, Arrizabalaga O, Serrano M, Lovell-Badge R, Matheu A. Increased gene dosage of Ink4/Arf and p53 delays age-associated central nervous system functional decline. Aging Cell (2015) 14(4):710-4. doi:10.1111/ acel. 12343

Conflict of Interest Statement: The authors declare that the research was conducted in the absence of any commercial or financial relationships that could be construed as a potential conflict of interest.

Copyright (๑) 2016 Garros-Regulez, Garcia, Carrasco-Garcia, Lantero, Aldaz, Moreno-Cugnon, Arrizabalaga, Undabeitia, Torres-Bayona, Villanua, Ruiz, Egaña, Sampron and Matheu. This is an open-access article distributed under the terms of the Creative Commons Attribution License (CC BY). The use, distribution or reproduction in other forums is permitted, provided the original author(s) or licensor are credited and that the original publication in this journal is cited, in accordance with accepted academic practice. No use, distribution or reproduction is permitted which does not comply with these terms. 